\title{
Risk of rheumatoid arthritis diagnosis in statin users in a large nationwide US study
}

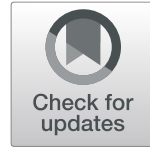

\author{
Madeline N. Peterson ${ }^{1}$, Hayley J. Dykhoff', Cynthia S. Crowson ${ }^{1,3}$, John M. Davis III', \\ Lindsey R. Sangaralingham ${ }^{2}$ and Elena Myasoedova ${ }^{1,3^{*}}$
}

\begin{abstract}
Objective: To evaluate the association between statin use and the risk of developing rheumatoid arthritis (RA) in a large, US case-control study.

Methods: Using the OptumLabs Data Warehouse, RA cases were identified as patients aged $\geq 18$ years with $\geq 2$ RA diagnoses between January 1, 2010 and June 30, 2019 and $\geq 1$ prescription fills for methotrexate within 1 year of the first RA diagnosis. The first RA diagnosis was the index date. Cases were matched 1:1 to controls on age, sex, region, year of index date, and length of baseline coverage. Statin users were defined by having $\geq 2$ statin prescription fills at least 90 days pre-index. Patients identified as statin users were further classified by statin user status (current or former), statin use duration, and intensity of statin exposure. Odds ratios for RA risk with statin use were estimated using logistic regression.
\end{abstract}

Results: 16,363 RA cases and 16,363 matched controls were identified. Among RA cases, 5509 (33.7\%) patients were statin users compared to 5164 (31.6\%) of the controls. Statin users had a slightly increased risk of RA compared to non-users (OR 1.12, 95\% Cl 1.06-1.18), and former statin users had an increased RA risk compared to current users (OR 1.21, 95\% Cl 1.13-1.28). However, risk was eliminated following adjustment for hyperlipidemia. The risk estimates for statin use duration and intensity did not reach significance.

Conclusion: This study demonstrates no significant increase in the risk of developing RA for statin users compared to non-users after adjustment for hyperlipidemia in addition to other relevant confounders. However, more information from prospective studies would be necessary to further understand this relationship.

Keywords: Rheumatoid arthritis, Lipid-lowering medications, Risk factors

\section{Background}

Statins, or 3-hydroxy-3-methylglutaryl coenzyme A (HMG-CoA) reductase inhibitors, are among the most widely prescribed drugs in the US [1] and are proven to reduce the risk of cardiovascular morbidity and mortality by inhibiting cholesterol synthesis [2-6]. In addition, there is growing data on the pleiotropic effects of statin

\footnotetext{
* Correspondence: myasoedova.elena@mayo.edu

'Division of Rheumatology, Mayo Clinic, 200 First Street SW, Rochester, MN 55905, USA

${ }^{3}$ Department of Quantitative Health Sciences, Mayo Clinic, 200 First Street SW, Rochester, MN 55905, USA

Full list of author information is available at the end of the article
}

use. Statins have been shown to modify a range of nonlipid-related cell signaling pathways, including those involved in eliciting inflammatory responses [7, 8].

The anti-inflammatory and immunomodulatory effects of statins have been observed in randomized controlled trials and observational studies in the general population [9] and in patients with chronic inflammatory diseases, such as rheumatoid arthritis (RA) [10-13]. In RA patients, statins have been shown to reduce C-reactive protein levels, joint inflammation, and overall disease activity $[12,14-16]$. 
In contrast, results of a systematic review compiling reports from long-term statin users found that statins may induce autoimmunity and predispose patients to the development of rheumatic conditions, such as systemic lupus erythematosus, dermatomyositis, and polymyositis [17]. Literature regarding the role of statins in the development of RA is conflicting with studies reporting a harmful $[18,19]$, protective [20-22], or neutral effect [23-25] on incident RA. A recent meta-analysis summarizing findings from observational studies in mainly European populations showed no difference in the risk of RA in statin users versus non-users [26]. Large studies examining the association between statin use and RA risk in the US are lacking.

This nation-wide case-control study aimed to evaluate the effects of statins on the development of RA and intended to specifically assess the influence of statin use duration and intensity, as well as the potential confounding of comorbidities, particularly hyperlipidemia.

\section{Methods}

\section{Data source}

This study used the OptumLabs Data Warehouse, a large administrative database containing de-identified health information for commercially insured and Medicare Advantage beneficiaries. This database represents a diverse mixture of ages, races/ethnicities, and geographical regions across the US and contains longitudinal information on enrollees, such as medical and pharmacy claims, laboratory results, and enrollment records [27]. Institutional Review Board approval was not required because the data have been de-identified.

\section{Case definition and selection}

Cases were defined as individuals aged $\geq 18$ years who had two or more claims containing an RA diagnostic code [International Classification of Disease (ICD)-9: 714.0, 714.1, 714.2; ICD-10: M05.xxx, M06.0xx, M06.8x, M06.9] between January 1, 2010 and June 30, 2019 with diagnoses being at least 30 days but no more than 365 days apart and one or more prescription fills for methotrexate (MTX) within 30 days before and 365 days after the first RA diagnosis. RA cases were required to have at least 365 days of medical and pharmacy insurance coverage prior to the first RA diagnosis; patients without this baseline period of coverage were considered prevalent RA patients and were excluded. Patients were excluded if they had an RA diagnostic code and/or a prescription fill for a disease-modifying antirheumatic drug (DMARD) any time during coverage prior to the first RA diagnosis and/or a prescription fill for MTX any time prior to 30 days before the first RA diagnosis. The date of the first RA diagnostic code was used as the index date (Fig. 1).

\section{Control definition and matching}

Controls were individuals aged $\geq 18$ years who had one or more claims for an evaluation and management visit during the study period and at least 365 days of baseline insurance coverage prior to the claim date. Of the claims that met the insurance criteria, one was randomly selected as the index date for each patient. Patients with an RA diagnostic code and/or DMARD prescription fill (including MTX) any time during their insurance coverage were excluded. Controls were matched 1:1 with RA cases on exact age, sex, geographical region, calendar year of index date, and length of baseline insurance coverage (within 30 days).

\section{Statin use assessment}

Statin users and non-users were identified using prescription fill data. Statin users were patients with two or more statin fills between the start of insurance coverage and 90 days pre-index date. Patients with one or zero fills during this period and those who started statins within 90 days of the index date were considered nonusers. For every statin prescription fill, the count day supply included in the prescription fill was defined as the number of statin days (NSD). Statin users with remaining statin supply based on the prescription fill and NSD at the time of index were considered current users. Statin users without available statin supply at the time of index were considered former users. In addition, statin users with a statin fill during the first 120 days of insurance coverage were considered prevalent users; users who did not have a first statin fill until after this period were considered incident users.

The total duration of statin use was determined by linking the patients' statin prescription fill dates and summing the NSD periods. If the next prescription fill date was within 30 days of the NSD, the patient was considered a continuous user, and the periods between prescription fills were summed into a single duration. If the patient did not have a subsequent statin fill within 30 days of the NSD, the last day of the patient's statin supply was recorded as the statin stop date. Patients who stopped and later resumed statin therapy, either once or multiple times, may have several start and stop dates. For these patients, the periods between each set of start and stop dates were summed to calculate the total duration of statin use. Duration of statin use was divided into three categories: <1 year, $\geq 1$ year, or unknown. Because prevalent users had a statin fill within the first 120 days of coverage, the true statin start date was unknown, and it was not possible to determine the total duration of statin use for these patients. Prevalent users who used statins for less than 1 year during coverage were placed into the unknown duration group. However, prevalent users who used statins for 1 year or more during 


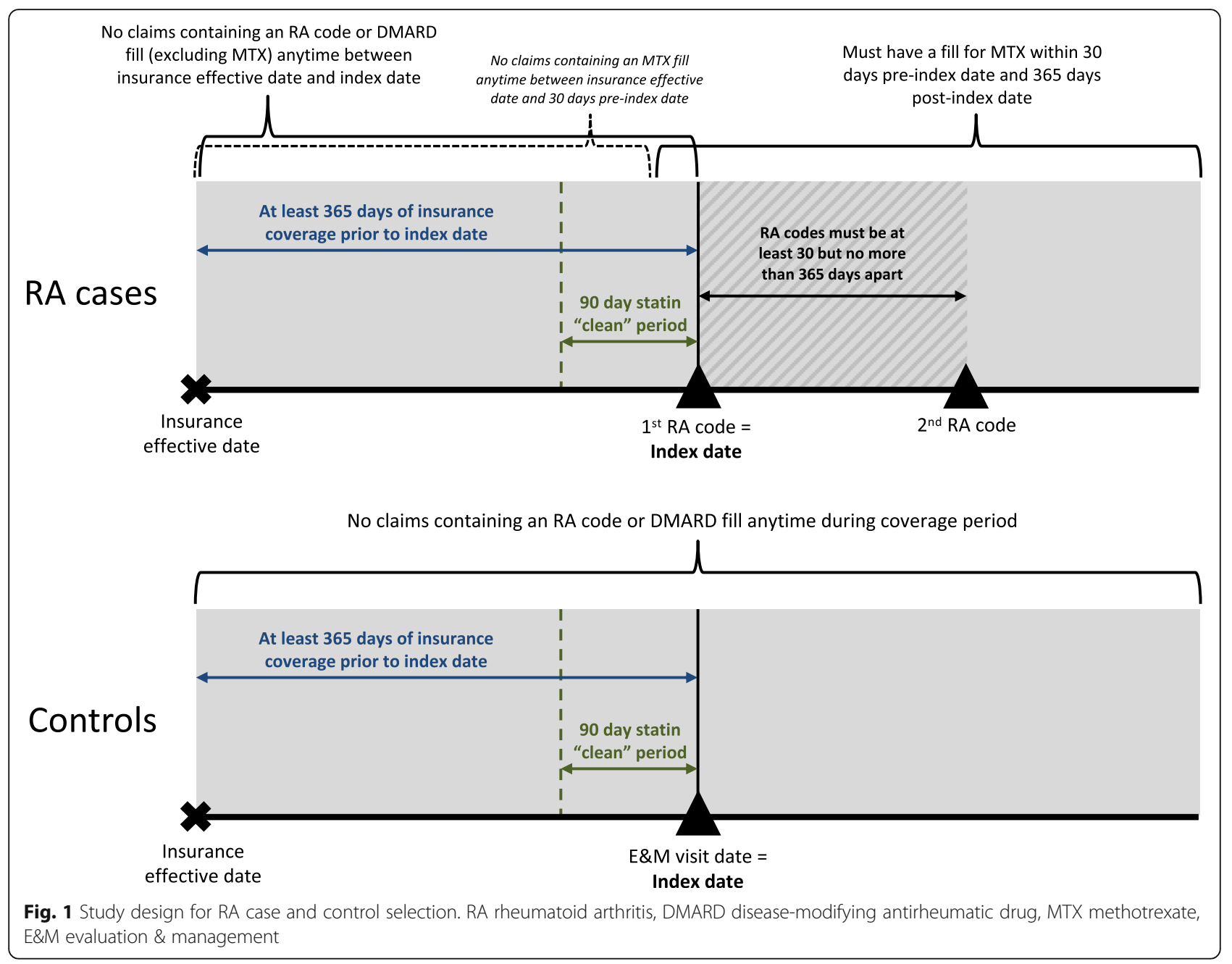

coverage could still be accurately placed into the $\geq 1$ year duration group.

The intensity of statin exposure was also evaluated. Using existing guidelines [28], statin intensity was divided into three categories according to the typical lowdensity lipoprotein cholesterol (LDL-C) reduction level: $\geq 50 \%$ reduction was classified as high intensity, 30-49\% as medium, and $<30 \%$ as low. A detailed table of intensity classifications for various medications and dosages is available online (Table S1). Statin intensity for each patient was defined according to the highest intensity statin ever filled by the patient.

\section{Potential confounders}

Diagnostic codes were used to compute the Charlson and Elixhauser Comorbidity Indices [29, 30], which are well-established methods for quantifying the burden of comorbidity. Rheumatic disease was omitted from both indices. Hyperlipidemia was also defined using diagnostic codes. All baseline comorbidities were identified via ICD-9/10 diagnostic codes during a screening period from 365 days pre-index date through 1 day pre-index date. Obesity and smoking were also defined using diagnostic codes any time between the insurance effective date and the index date, as data on body mass index (BMI) and patient-reported smoking status were not available for the majority of patients. The diagnostic code set to identify smoking status was developed previously [31]. For the subset of patients with available laboratory data, the closest LDL-C level measured prior to the index date was used in the analysis.

\section{Statistical analysis}

Descriptive statistics were used to summarize the data. Logistic regression models were used to estimate odds ratios (OR) and 95\% confidence intervals (CI) for the effect of statin use on the development of RA. Outcomes were adjusted for age, sex, race/ethnicity, calendar year of index date, and geographical region. In addition, two models included comorbidity adjustments using the Charlson and Elixhauser Comorbidity Indices. 
Numerous sensitivity analyses were performed with regard to outcome definition, inclusion criteria, intensity assessment, and potential confounders. Two sensitivity analyses were performed for the RA definition: one analysis specified that the RA diagnosis must come from a rheumatologist, and a second analysis loosened the original definition by allowing RA patients to use any DMARD in the year after diagnosis, instead of strictly MTX. To assess the effect of age on RA risk, a subgroup analysis was performed observing the risk in patients aged $\geq 40$ years. To investigate the potential confounding of hyperlipidemia, two analyses were performed. First, risk estimates were individually adjusted for hyperlipidemia via diagnostic codes (ICD-9 272.0-272.4, ICD-10 E78.0x-E78.5). Second, an analysis was performed using a subset of the original population who had laboratory data for lipid levels. Risk estimates for this subgroup were adjusted for LDL-C levels instead of hyperlipidemia diagnostic codes. To assess any residual confounding of comorbidities, a sensitivity analysis adjusted for the following ten conditions as independent variables: obesity, myocardial infarction, cerebrovascular disease, congestive heart failure, peripheral vascular disease, diabetes, hypothyroidism, liver disease, metastatic cancer, and renal failure. The influence of smoking was also investigated. Lastly, an analysis was performed using the intensity of the most recently filled statin as the intensity variable. Analyses were performed using SAS version 9.4 (SAS Institute, Cary, NC, USA).

\section{Results}

Using the OptumLabs Data Warehouse, 51,585,875 patients with Medicare Advantage or commercial medical and pharmacy enrollment between January 1, 2010 and June 30, 2019 were identified. Of these, 523,721 had a claim containing an RA code during the study period. Excluding patients who did not meet the inclusion criteria yielded 16,459 eligible RA patients. There were 19,987,392 eligible control patients. After 1:1 matching, 16,363 RA cases and 16,363 controls were included in this study (Fig. 2).

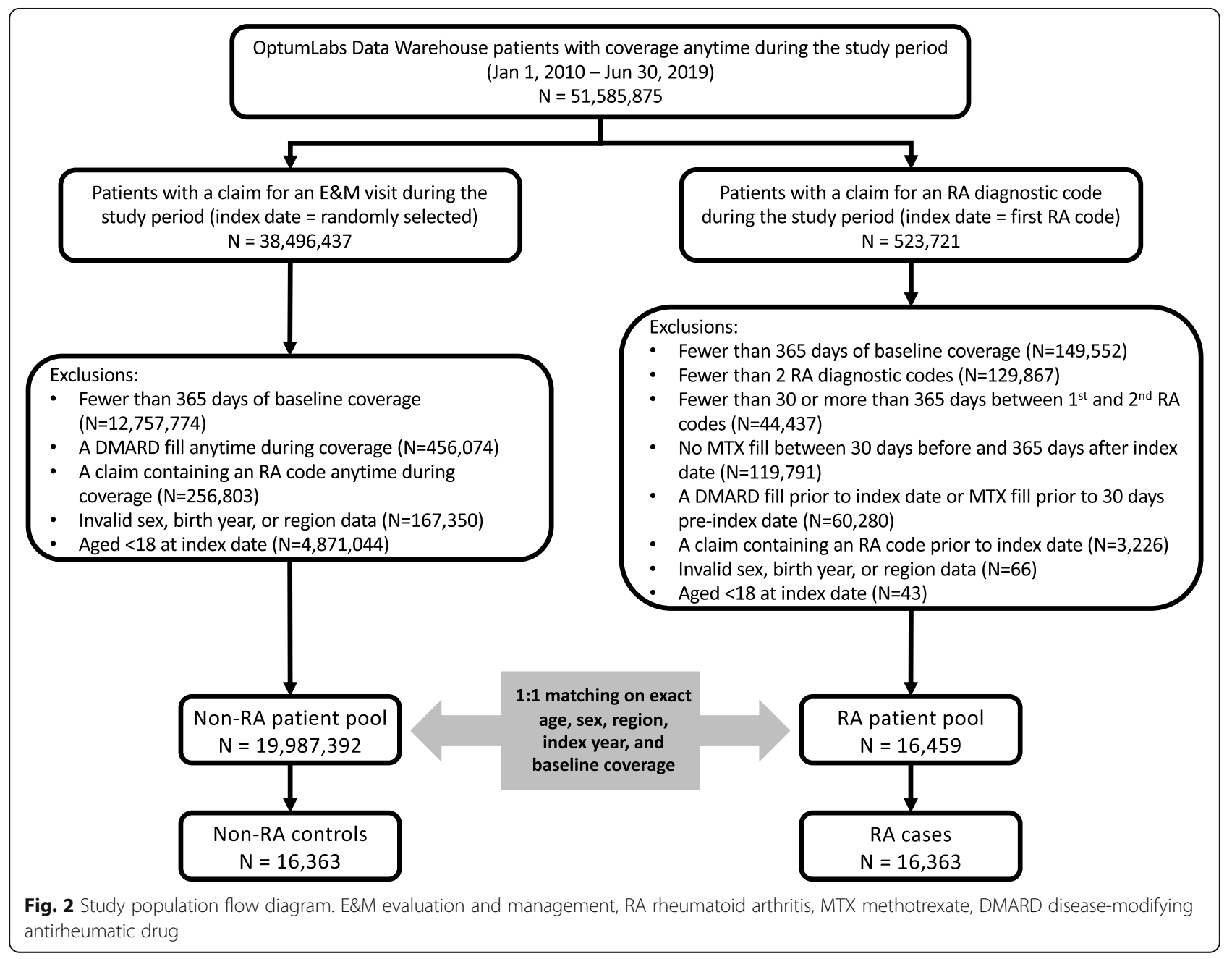


Cases and controls had equivalent or similar baseline characteristics and comparable distributions of comorbidities (Table 1). Both populations consisted of predominantly white females $(70.7 \%$ female, RA cases $73.6 \%$ white, non-RA controls $74.2 \%$ white). Among RA cases, $5509(33.7 \%)$ were found to be statin users versus 5164 (31.6\%) of the controls (Table 2). The distribution of current and former users among cases and controls was similar; there were slightly more former users among RA cases and slightly more current users among controls. The majority of statin users, with and without RA, had at least one full year of statin use at the time of index. In addition, the highest statin dosage ever filled for most statin users was a medium intensity statin.

Statin use was associated with a modest increase in the risk of RA (OR 1.12, 95\% CI 1.06-1.18 [adjusted for age, sex, race/ethnicity, index year, and region]). This difference persisted following additional adjustment for the Charlson (OR 1.14, 95\% CI 1.08-1.20) and Elixhauser (OR 1.07, 95\% CI 1.01-1.13) Comorbidity Indices. However, this increased risk was eliminated following additional adjustment for hyperlipidemia (OR 0.95, 95\% CI 0.90-1.01). Compared to those who did not use statins, former users had a greater risk of developing RA (OR 1.21, 95\% CI 1.13-1.28), whereas current statin users had no increase in risk (OR 1.03, 95\% CI 0.97 1.10). Following adjustment for hyperlipidemia, former users had no increased RA risk (OR 1.03, 95\% 0.96$1.10)$ and current users had a slightly decreased risk (OR $0.87,95 \%$ CI 0.81-0.93). Patients who used statins for $<1$ year had a slightly increased risk compared to those who used statins for $\geq 1$ year, but this difference did not reach

Table 1 Baseline characteristics of rheumatoid arthritis cases and controls

\begin{tabular}{|c|c|c|}
\hline & Cases $(n=16,363)$ & Controls $(n=16,363)$ \\
\hline Age (years), mean (SD) & $58.2(14.1)$ & $58.2(14.1)$ \\
\hline \multicolumn{3}{|l|}{ Sex, $n(\%)$} \\
\hline Female & $11565(70.7)$ & $11565(70.7)$ \\
\hline Male & $4798(29.3)$ & $4798(29.3)$ \\
\hline \multicolumn{3}{|l|}{ Race/ethnicity, $\boldsymbol{n}$ (\%) } \\
\hline Asian & $437(2.7)$ & $640(3.9)$ \\
\hline Black & $1572(9.6)$ & $1542(9.4)$ \\
\hline Hispanic & $1822(11.1)$ & $1448(8.8)$ \\
\hline White & $12039(73.6)$ & $12147(74.2)$ \\
\hline Other/unknown & $493(3.0)$ & $586(3.6)$ \\
\hline \multicolumn{3}{|l|}{ Region, $n(\%)$} \\
\hline Midwest & $4185(25.6)$ & $4185(25.6)$ \\
\hline Northeast & $1800(11.0)$ & $1800(11.0)$ \\
\hline South & $8185(50.0)$ & $8185(50.0)$ \\
\hline West & $2193(13.4)$ & $2193(13.4)$ \\
\hline Baseline insurance coverage (years), mean (SD) & $4.1(3.0)$ & $4.1(3.0)$ \\
\hline \multicolumn{3}{|l|}{ Disease history, $n$ (\%) } \\
\hline Hyperlipidemia & $7848(48.0)$ & $6935(42.4)$ \\
\hline Myocardial infarction & $378(2.3)$ & $423(2.6)$ \\
\hline Cerebrovascular disease & $1086(6.6)$ & $1038(6.3)$ \\
\hline Congestive heart failure & $793(4.8)$ & $887(5.4)$ \\
\hline Peripheral vascular disorders & $1326(8.1)$ & $1177(7.2)$ \\
\hline Diabetes & $3331(20.4)$ & $3092(18.9)$ \\
\hline Hypothyroidism & $3481(21.3)$ & $2687(16.4)$ \\
\hline Liver disease & $783(4.8)$ & $676(4.1)$ \\
\hline Metastatic cancer & $74(0.5)$ & $240(1.5)$ \\
\hline Obesity & $2466(15.1)$ & $1917(11.7)$ \\
\hline Renal failure & $862(5.3)$ & $993(6.1)$ \\
\hline Charlson index score, mean (SD) & $2.2(1.9)$ & $2.3(2.2)$ \\
\hline Elixhauser index score, mean (SD) & $2.4(2.3)$ & $2.2(2.5)$ \\
\hline
\end{tabular}


Table 2 Risk of rheumatoid arthritis in statin users compared to non-users

\begin{tabular}{|c|c|c|c|c|c|c|}
\hline Exposure & Cases $(n=16,363)$ & Controls $(n=16,363)$ & $\mathrm{OR}^{1}(95 \% \mathrm{Cl})$ & $\mathrm{OR}^{2}(95 \% \mathrm{Cl})$ & $\mathrm{OR}^{3}(95 \% \mathrm{Cl})$ & $\mathrm{OR}^{4}(95 \% \mathrm{Cl})$ \\
\hline \multicolumn{7}{|l|}{ Statin user status } \\
\hline Non-user & 10854 & 11199 & 1.00 & 1.00 & 1.00 & 1.00 \\
\hline Statin user & 5509 & 5164 & $1.12(1.06,1.18)$ & $1.14(1.08,1.20)$ & $1.07(1.01,1.13)$ & $0.95(0.90,1.01)$ \\
\hline Current user & $2629(47.7)$ & $2680(51.9)$ & $1.03(0.97,1.10)$ & $1.05(0.98,1.12)$ & $0.98(0.92,1.05)$ & $0.87(0.81,0.93)$ \\
\hline Former user & $2880(52.3)$ & $2484(48.1)$ & $1.21(1.13,1.28)$ & $1.23(1.15,1.31)$ & $1.15(1.08,1.23)$ & $1.03(0.96,1.10)$ \\
\hline \multicolumn{7}{|l|}{ Statin use duration } \\
\hline$<1$ year statin use & $996(18.1)$ & $856(16.6)$ & $1.20(1.09,1.33)$ & $1.22(1.11,1.34)$ & $1.16(1.05,1.27)$ & $1.04(0.94,1.15)$ \\
\hline$\geq 1$ year statin use & $3917(71.1)$ & 3795 (73.5) & $1.08(1.02,1.15)$ & $1.10(1.04,1.17)$ & $1.04(0.98,1.10)$ & $0.91(0.86,0.97)$ \\
\hline Unknown & $596(10.8)$ & $513(9.9)$ & $1.20(1.07,1.36)$ & $1.23(1.09,1.39)$ & $1.14(1.01,1.29)$ & $1.02(0.90,1.16)$ \\
\hline \multicolumn{7}{|l|}{ Statin use intensity } \\
\hline Low & $519(9.4)$ & $505(9.8)$ & $1.08(0.95,1.23)$ & $1.10(0.97,1.25)$ & $1.04(0.91,1.18)$ & $0.93(0.82,1.06)$ \\
\hline Medium & $3486(63.3)$ & $3290(63.7)$ & $1.11(1.05,1.18)$ & $1.12(1.06,1.19)$ & $1.07(1.01,1.13)$ & $0.95(0.89,1.01)$ \\
\hline High & $1504(27.3)$ & $1369(26.5)$ & $1.15(1.06,1.25)$ & $1.18(1.09,1.28)$ & $1.08(1.00,1.18)$ & $0.96(0.88,1.05)$ \\
\hline
\end{tabular}

${ }^{1}$ Model 1: Adjusted for age, sex, race/ethnicity, calendar year of index date, and geographical region

${ }^{2}$ Model 2: Model $1+$ adjustment for Charlson Comorbidity Index

${ }^{3}$ Model 3: Model $1+$ adjustment for Elixhauser Comorbidity Index

${ }^{4}$ Model 4: Model 3 + adjustment for hyperlipidemia

statistical significance in any of the models. A slight dose-response relationship between statin intensity and RA was observed. However, this trend did not reach significance. Results were similar in the analysis for the intensity of the most recently filled statin (Table S2).

In the additional sensitivity analysis for hyperlipidemia, which included only individuals who had laboratory data for LDL-C, 6948 RA cases and 6948 matched controls were identified. In both cases and controls, 2862 (41.2\%) individuals were found to be statin users. In this subgroup assessment, the risk of RA, prior to additional adjustment, was not elevated (OR 1.00, 95\% CI 0.93-1.08). When risk estimates were individually adjusted for LDL$C$ level, they remained unchanged. Sensitivity analyses for RA definition, age, additional comorbidities, and smoking produced results consistent with the initial findings (Table S2).

\section{Discussion}

To the authors' knowledge, this is the first large casecontrol study to evaluate the relationship between statin use and RA risk in the US. Findings of this study demonstrate that statin use is associated with a modest increase in the risk of developing RA, but following adjustment for hyperlipidemia, this risk is diminished. Former statin users had an increased risk of RA versus current statin users. Patients who used statins for $<1$ year were found to have a slightly increased risk of RA versus those who used statins for $\geq 1$ year. A slight doseresponse relationship was observed for statin intensity and RA risk. However, the trends for statin use duration and intensity did not reach statistical significance, and no subgroup had a meaningfully increased risk following hyperlipidemia adjustment.

The reduction in risk seen with hyperlipidemia adjustment warrants further discussion. Prior literature suggests that hyperlipidemia may serve as an independent risk factor for RA [21], and the results of this study appear to support the notion that an increased RA risk may be due to hyperlipidemia and not statin use. However, it is important to consider that many patients receive a hyperlipidemia diagnosis during the initiation of statin treatment, and therefore, any attenuation in risk resulting from hyperlipidemia adjustment may not reflect a true association. With the exception of one prior study [19], no comparative study reported an analysis that specifically assessed the influence of hyperlipidemia/ cholesterol values as an independent variable in adjustments. Therefore, it is unknown how hyperlipidemia impacted risk estimates in prior studies and if any consequential change in risk reflected a true association.

If the reduction in risk following hyperlipidemia adjustment is artifactual, the underlying mechanism for how statins may facilitate RA development is unknown. Some evidence suggests that statins may disrupt immune homeostasis by directly affecting $\mathrm{T}$ cells and inducing a shift from Th1 to Th2 immune responses [32, 33]. This may lead to B cell hyperactivity and trigger the production of autoantibodies [34, 35]. In addition, the burden of infections over time, compounded by a reduced Th1 response, may foster breakdown of self-tolerance, as infectious agents cannot be cleared as effectively as they would be under normal conditions [36]. Another possibility is that statins, being pro-apoptotic agents, may be capable of activating or exacerbating cellular apoptosis 
[37-41]. The release of endoplasmic and endonuclear antigens into circulation during cell death may induce the production of pathogenic autoantibodies [42, 43]. Cardiovascular risk factors, such as hyperlipidemia, may also play a role, as data has shown that patients who later develop RA tend to have significantly more atherogenic lipid profiles [44]. Therefore, statin use may be a proxy for hyperlipidemia, and thus, the unfavorable lipid conditions may be responsible for the association with increased RA risk, potentially through the chain of proinflammatory and immunogenic reactions [45-47]. These mechanisms for loss of tolerance would likely not induce autoimmunity on their own, but they may result in an earlier diagnosis or influence the progression of a condition, such as RA, in those who are already prone to the development of an autoimmune disease [18].

Of the studies that have previously investigated this topic, two found statins to have a harmful effect, three demonstrated a protective effect, and three observed no clear impact on the risk of incident RA. A retrospective cohort study of 511,620 statin users, which observed an increased risk of RA in statin users compared to nonusers, also observed a greater RA risk for recent users compared to current users [19]; this aligns with the observation of an increased RA risk in former versus current users in the present study. With the exception of this one similarity, the present study does not seem to clearly support or refute the findings from any prior study that has investigated this topic, as the results have been largely heterogeneous overall. Therefore, it seems necessary to further discuss key methodological differences between the present and prior studies that could account for the conflicting data.

First, lack of non-statin reference groups: Two prior studies, showing a protective effect of statins against RA, compared statin users depending on persistence with treatment [20] and treatment intensity [22], precluding direct comparison with the current study.

Second, variability in definitions of outcome and exposure: Compared to prior studies, the present study used a more specific and exclusive RA definition that was selected in order to avoid misclassifying patients with conditions that present similarly to RA, as this may have been an issue in other studies. Sensitivity analyses with regard to the RA definition produced similar results. The definition of statin exposure also varied among studies. While the current study required at least two statin prescription fills for statin users, several prior studies required only one statin fill or did not define a minimum exposure requirement [19, 20, 22-25]. Some of these studies may have included users with near negligible periods of statin exposure, which may explain the inconsistencies in the findings. When the statin user requirement was changed to only one prescription fill, the results remained unchanged. However, in this study, statin users were identified by the number of statin fills, while other studies had to rely on prescription data without information on whether the statin was actually filled. Therefore, it is possible that a similar change to the statin user definition may have a meaningful impact on risk estimates in other studies. Lastly, there was variation in the considerations for potential lag-times. Assuming that statin exposure is unlikely to influence the risk of RA immediately after initiating treatment, RA cases diagnosed within 90 days of starting statins were excluded. Previous studies that did not account for this delay may have included patients whose RA symptoms predated the initiation of statin therapy. There is also an assumed delay between symptom onset and RA diagnosis. Chan et al. [48] estimated a median delay from RA onset to diagnosis of approximately 36 weeks; thus, many patients may have developed RA months or years prior to the recorded event date. However, several previous studies have considered the impacts of this delay, and the results remained largely unchanged in all studies [18, 19, $21,22]$.

Third, consideration for potential confounders: Similar to four previous studies [18-20,22], the current study excluded RA patients with DMARD use before the index date and non-RA patients with any DMARD use. Studies not excluding for DMARD use may have resulted in inaccurate classifications of RA and non-RA patients. This study considered a more comprehensive list of preexisting conditions as potential confounders through the use of two comorbidity indices. Adjustments for the Charlson and Elixhauser Comorbidity Indices did not significantly alter the results. One other study accounted for a comorbidity index [24], but the reported comorbidity scores were much lower than in the present study. This was likely due to the younger age of patients in that study conducted within a military health care system and may explain the result discrepancies with the present study. When ten additional comorbidities were added to adjustments as independent variables, the risk remained unchanged. Consideration for the influence of hyperlipidemia, as previously mentioned, was another important factor that may explain the different results.

Simvastatin $10 \mathrm{mg}$ has been available over-the-counter since 2004 in the UK. Four studies were conducted in UK populations with study periods during this time [19, $22,23,25]$. The current study was performed in the US, where statins are available via prescription only. Overthe-counter statin use may have led to an underestimation of statin exposure in both user and non-user populations. It is unknown how this may have impacted the findings in those studies.

Fourth, biases: Berkson's bias may have influenced the results, as joint pains may have prompted a thorough 
work-up that resulted in statin initiation prior to a subsequent diagnosis of RA. Ascertainment bias may have also influenced the results. As noted by de Jong and colleagues [19], some patients who recently begin statin therapy may experience muscle-related symptoms [49], which may lead to a greater number of clinical visits, including rheumatology referrals. Thus, statin users may have been more likely to be diagnosed with RA than non-users.

Strengths of this study include its large and representative sample size with $>16,000$ RA patients, more than any prior study on this topic. The strong comparability due to exact matching of cases and controls likely reduced measured and unmeasured confounding. A large range of sensitivity analyses were performed, producing largely consistent results, which suggests minimal impact of residual confounders. Lastly, this study was specifically designed to assess RA as an outcome of statin use by comparing statin users to non-users. Many of the prior studies examined additional outcomes or did not utilize a non-user reference group.

There are several potential limitations of this study. First, this was a retrospective, observational study, and the use of statins was not randomized. In addition, statin use was determined via prescription fill data. However, as previously mentioned, many administrative data sources rely on prescription data without information on whether the prescription was actually filled, so others may have overestimated statin use even more than the current study. Case-control studies are limited in that they cannot be used to calculate incidence and are not suitable to imply causation. However, considering the low prevalence of RA among the general population, a case-control study seemed to have greater power to assess this association compared to alternatives, such as a retrospective cohort study. Limited information was available on rheumatoid factor or anti-cyclic citrullinated peptide antibodies and on lifestyle factors (e.g., diet, physical activity), which may be important risk factors for RA [50, 51]. Adjustments for smoking and obesity did not have an impact on risk estimates. However, smoking, obesity, and comorbidities were determined via diagnostic codes and could not be verified with clinical data, such as BMI, blood pressure, glucose levels, or inflammatory markers. Finally, duration and intensity assessments were limited by the large number of prevalent statin users in this study. The duration of statin use was unknown for some of these patients, so the actual number of individuals in both duration groups should be higher. Although the sensitivity analysis for intensity produced consistent results, it was not possible to accurately perform a cumulative exposure assessment to examine the impacts of differential statin intensity use over time.

\section{Conclusion}

In summary, the results of this nation-wide study suggest there is no significant increase in the risk of RA occurrence in statin users, adjusting for hyperlipidemia in addition to other relevant confounders. The current body of conflicting data on this topic demonstrates the challenge of performing a retrospective analysis on the relationship between a prescription drug and an unrelated medical disease. This endeavor becomes increasingly difficult in the case of RA due to its minimal prevalence in the general population, shaded symptomology, and multifactorial etiology. Taken together with the heterogeneous results of other reports, this study does not indicate or support any change to the current clinical recommendations for prescribing statins.

\section{Abbreviations}

HMG-CoA: 3-Hydroxy-3-methylglutaryl coenzyme A; RA: Rheumatoid arthritis; ICD: International classification of disease; MTX: Methotrexate; DMARD: Diseasemodifying antirheumatic drug; NSD: Number of statin days; LDL-C: Low-density lipoprotein cholesterol; BMI: Body mass index; OR: Odds ratio; Cl: Confidence interval

\section{Supplementary Information}

The online version contains supplementary material available at https://doi. org/10.1186/s13075-021-02617-5.

Additional file 1: Supplementary Table 1. Intensity classification for

various statin medications and dosages

Additional file 2: Supplementary Table 2. Sensitivity analyses to assess the stability of findings

\section{Acknowledgements}

Not applicable

\section{Authors' contributions}

MP was involved in the analysis and interpretation of the data and was largely responsible for drafting and revising this manuscript. HD was involved in the design of the work and largely responsible for the acquisition and analysis of the data. CC was highly involved in the conception and design of the work, as well as analysis and interpretation of the results. She also played an important role in drafting and revising this manuscript. JD was involved in the conception and design of the work, as well as analysis and interpretation of the results. LS played an important role in the design of the work and the acquisition of the data. EM was highly involved in the conception and design of the work, as well as analysis and interpretation of the results. She also played an important role in drafting and revising this manuscript. All authors agree to be personally accountable for one's own contributions and to ensure any questions related to the work are appropriately investigated and resolved. The authors have read and approved the final manuscript.

\section{Funding}

This work was supported by grants from the National Institutes of Health, National Institute of Arthritis and Musculoskeletal and Skin Diseases (R01 AR46849), and National Institutes of Health, National Institute on Aging (R01 AG034676). The content of this manuscript is solely the responsibility of the authors and does not necessarily represent the official views of the National Institutes of Health. Dr. Elena Myasoedova is supported by the Career Development Award funded by the Louis V. Gerstner, Jr. Fund at Vanguard Charitable and R01 AG068192. 


\section{Availability of data and materials}

The data used and analyzed in the current study are available from OptumLabs through the OptumLabs Data Warehouse (OLDW). Restrictions apply to the availability of these data, which were used under license for the current study and therefore are not publicly available. However, the data are available from the authors upon reasonable request and with permission from OptumLabs.

\section{Declarations}

\section{Ethics approval and consent to participate}

Institution Review Board approval was not required for this study, as all data have been de-identified.

\section{Consent for publication}

Not applicable

\section{Competing interests}

The authors declare that they have no competing interests relevant to the current study.

\section{Author details}

'Division of Rheumatology, Mayo Clinic, 200 First Street SW, Rochester, MN 55905, USA. ${ }^{2}$ Robert D. and Patricia E. Kern Center for the Science of Health Care Delivery, Mayo Clinic, 200 First Street SW, Rochester, MN 55905, USA. ${ }^{3}$ Department of Quantitative Health Sciences, Mayo Clinic, 200 First Street SW, Rochester, MN 55905, USA.

\section{Received: 25 March 2021 Accepted: 25 August 2021}

\section{Published online: 18 September 2021}

\section{References}

1. Kantor ED, Rehm CD, Haas JS, Chan AT, Giovannucci EL. Trends in prescription drug use among adults in the United States from 1999-2012. Jama. 2015;314(17):1818-31. https://doi.org/10.1001/jama.2015.13766.

2. Istvan ES, Deisenhofer J. Structural mechanism for statin inhibition of HMGCoA reductase. Science. 2001;292(5519):1160-4. https://doi.org/10.1126/ science.1059344.

3. Sever PS, Dahlöf B, Poulter NR, Wedel H, Beevers G, Caulfield M, et al. Prevention of coronary and stroke events with atorvastatin in hypertensive patients who have average or lower-than-average cholesterol concentrations, in the Anglo-Scandinavian Cardiac Outcomes Trial--Lipid Lowering Arm (ASCOT-LLA): a multicentre randomised controlled trial. Lancet. 2003;361(9364):1149-58. https://doi.org/10.1016/S0140-6736(03)1294 8-0.

4. Ridker PM, Danielson E, Fonseca FA, Genest J, Gotto AM Jr, Kastelein JJ, et al. Rosuvastatin to prevent vascular events in men and women with elevated C-reactive protein. N Engl J Med. 2008;359(21):2195-207. https:// doi.org/10.1056/NEJMoa0807646.

5. Long-Term Intervention with Pravastatin in Ischaemic Disease (LIPID) Study Group. Prevention of cardiovascular events and death with pravastatin in patients with coronary heart disease and a broad range of initial cholesterol levels. N Engl J Med. 1998;339(19):1349-57. https://doi.org/10.1056/NEJM1 99811053391902.

6. Downs JR, Clearfield M, Weis S, Whitney E, Shapiro DR, Beere PA, et al. Primary prevention of acute coronary events with lovastatin in men and women with average cholesterol levels: results of AFCAPS/TexCAPS. Air Force/Texas Coronary Atherosclerosis Prevention Study. JAMA. 1998;279(20): 1615-22. https://doi.org/10.1001/jama.279.20.1615.

7. Liao JK, Laufs U. Pleiotropic effects of statins. Annu Rev Pharmacol Toxicol. 2005;45(1):89-118. https://doi.org/10.1146/annurev.pharmtox.45.120403. 095748.

8. Abeles AM, Pillinger MH. Statins as antiinflammatory and immunomodulatory agents: a future in rheumatologic therapy? Arthritis Rheum. 2006;54(2):393-407. https://doi.org/10.1002/art.21521.

9. Ridker PM, Danielson E, Fonseca FA, Genest J, Gotto AM Jr, Kastelein JJ, et al. Reduction in C-reactive protein and LDL cholesterol and cardiovascular event rates after initiation of rosuvastatin: a prospective study of the JUPITER trial. Lancet. 2009;373(9670):1175-82. https://doi.org/10.1016/ S0140-6736(09)60447-5.
10. Li GM, Zhao J, Li B, Zhang XF, Ma JX, Ma XL, et al. The anti-inflammatory effects of statins on patients with rheumatoid arthritis: a systemic review and meta-analysis of 15 randomized controlled trials. Autoimmun Rev. 2018; 17(3):215-25. https://doi.org/10.1016/j.autrev.2017.10.013.

11. LV S, Liu Y, Zou Z, Li F, Zhao S, Shi R, et al. The impact of statins therapy on disease activity and inflammatory factor in patients with rheumatoid arthritis: a meta-analysis. Clin Exp Rheumatol. 2015;33(1):69-76.

12. Okamoto H, Koizumi K, Kamitsuji S, Inoue E, Hara M, Tomatsu T, et al. Beneficial action of statins in patients with rheumatoid arthritis in a large observational cohort. J Rheumatol. 2007;34(5):964-8.

13. Abud-Mendoza C, de la Fuente H, Cuevas-Orta E, Baranda L, Cruz-Rizo J, González-Amaro R. Therapy with statins in patients with refractory rheumatic diseases: a preliminary study. Lupus. 2003;12(8):607-11. https:// doi.org/10.1191/0961203303lu429oa.

14. McCarey DW, Mclnnes IB, Madhok R, Hampson R, Scherbakov O, Ford I, et al. Trial of atorvastatin in rheumatoid arthritis (TARA): double-blind, randomised placebo-controlled trial. Lancet. 2004;363(9426):2015-21. https://doi.org/10.1016/S0140-6736(04)16449-0.

15. Mowla K, Rajai E, Ghorbani A, Dargahi-Malamir M, Bahadoram M, Mohammadi S. Effect of atorvastatin on the disease activity and severity of rheumatoid arthritis: double-blind randomized controlled trial. J Clin Diagn Res. 2016;10(5):Oc32-6.

16. Tang TT, Song Y, Ding YJ, Liao YH, Yu X, Du R, et al. Atorvastatin upregulates regulatory $T$ cells and reduces clinical disease activity in patients with rheumatoid arthritis. J Lipid Res. 2011;52(5):1023-32. https:// doi.org/10.1194/jlr.M010876.

17. Noel B. Lupus erythematosus and other autoimmune diseases related to statin therapy: a systematic review. J Eur Acad Dermatol Venereol. 2007; 21(1):17-24. https://doi.org/10.1111/j.1468-3083.2006.01838.x.

18. de Jong $H J$, Klungel $O H$, van Dijk L, Vandebriel RJ, Leufkens $H G$, van der Laan JW, et al. Use of statins is associated with an increased risk of rheumatoid arthritis. Ann Rheum Dis. 2012;71(5):648-54. https://doi.org/ 0.1136/ard.2011.155622.

19. de Jong HJI, Cohen Tervaert JW, Lalmohamed A, de Vries F, Vandebriel RJ, van Loveren $\mathrm{H}$, et al. Pattern of risks of rheumatoid arthritis among patients using statins: a cohort study with the clinical practice research datalink. PLoS ONE. 2018;13(2):e0193297. https://doi.org/10.1371/journal.pone.01932 97.

20. Chodick G, Amital H, Shalem Y, Kokia E, Heymann AD, Porath A, et al. Persistence with statins and onset of rheumatoid arthritis: a populationbased cohort study. PLoS Med. 2010;7(9):e1000336. https://doi.org/10.1371/ journal.pmed.1000336.

21. Jick SS, Choi H, Li L, McInnes IB, Sattar N. Hyperlipidaemia, statin use and the risk of developing rheumatoid arthritis. Ann Rheum Dis. 2009;68(4):54651. https://doi.org/10.1136/ard.2008.091967.

22. Tascilar K, Dell'Aniello S, Hudson M, Suissa S. Statins and risk of rheumatoid arthritis: a nested case-control study. Arthritis Rheumatol. 2016;68(11):260311. https://doi.org/10.1002/art.39774.

23. Hippisley-Cox J, Coupland C. Unintended effects of statins in men and women in England and Wales: population based cohort study using the QResearch database. Bmj. 2010;340(may19 4):c2197. https://doi.org/10.1136/ bmj.c2197.

24. Schmidt T, Battafarano DF, Mortensen EM, Frei CR, Mansi I. Frequency of development of connective tissue disease in statin-users versus nonusers. Am J Cardiol. 2013;112(6):883-8. https://doi.org/10.1016/j.amjcard.2013.04. 059.

25. Smeeth L, Douglas I, Hall AJ, Hubbard R, Evans S. Effect of statins on a wide range of health outcomes: a cohort study validated by comparison with randomized trials. Br J Clin Pharmacol. 2009;67(1):99-109. https://doi.org/1 0.1111/j.1365-2125.2008.03308.x.

26. Myasoedova E, Karmacharya P, Duarte-Garcia A, Davis JM 3rd, Murad MH, Crowson CS. Effect of statin use on the risk of rheumatoid arthritis: a systematic review and meta-analysis. Semin Arthritis Rheum. 2020;50(6): 1348-56. https://doi.org/10.1016/j.semarthrit.2020.03.008.

27. OptumLabs. OptumLabs Data Warehouse (OLDW) Descriptions and Citation Cambridge, MA 2019.

28. Grundy SM, Stone NJ, Bailey AL, Beam C, Birtcher KK, Blumenthal RS, et al. 2018 AHA/ACC/AACVPR/AAPA/ABC/ACPM/ADA/AGS/APhA/ASPC/NLA/ PCNA guideline on the management of blood cholesterol: executive summary: a report of the American College of Cardiology/American Heart Association Task Force on Clinical Practice Guidelines. Journal of the 
American College of Cardiology. 2019;73(24):3168-209. https://doi.org/10.1 016/j.jacc.2018.11.002.

29. Charlson ME, Pompei P, Ales KL, MacKenzie CR. A new method of classifying prognostic comorbidity in longitudinal studies: development and validation. J Chronic Dis. 1987;40(5):373-83. https://doi.org/10.1016/0021-9681(87)901 71-8.

30. Elixhauser A, Steiner C, Harris DR, Coffey RM. Comorbidity measures for use with administrative data. Medical care. 1998;36(1):8-27. https://doi.org/10.1 097/00005650-199801000-00004.

31. Dempsey $T M$, Sangaralingham $L R$, Yao X, Sanghavi D, Shah ND, Limper AH. Clinical effectiveness of antifibrotic medications for idiopathic pulmonary fibrosis. Am J Respir Crit Care Med. 2019;200(2):168-74. https://doi.org/10.11 64/rccm.201902-04560C

32. Youssef S, Stüve O, Patarroyo JC, Ruiz PJ, Radosevich JL, Hur EM, et al. The HMG-CoA reductase inhibitor, atorvastatin, promotes a Th2 bias and reverses paralysis in central nervous system autoimmune disease. Nature. 2002;420(691 1):78-84. https://doi.org/10.1038/nature01158.

33. Arnaud C, Braunersreuther V, Mach F. Toward immunomodulatory and antiinflammatory properties of statins. Trends in Cardiovascular Medicine. 2005; 15(6):202-6. https://doi.org/10.1016/j.tcm.2005.07.002.

34. Noël B. Statins and lupus erythematosus. Rheumatology. 2004;43(3):397-8.

35. Mok CC, Lau CS. Pathogenesis of systemic lupus erythematosus. J Clin Pathol. 2003;56(7):481-90. https://doi.org/10.1136/jcp.56.7.481.

36. Kivity S, Agmon-Levin N, Blank M, Shoenfeld Y. Infections and autoimmunity - friends or foes? Trends Immunol. 2009;30(8):409-14. https://doi.org/10.101 6/j.it.2009.05.005

37. Jones KD, Couldwell WT, Hinton DR, Su YH, He SK, Anker L, et al. Lovastatin induces growth inhibition and apoptosis in human malignant glioma cells. Biochem Biophys Res Commun. 1994;205(3):1681-7. https://doi.org/10.1006/ bbrc.1994.2861.

38. Blanco-Colio LM, Villa A, Ortego M, Hernández-Presa MA, Pascual A, Plaza JJ, et al. 3-Hydroxy-3-methyl-glutaryl coenzyme A reductase inhibitors, atorvastatin and simvastatin, induce apoptosis of vascular smooth muscle cells by downregulation of $\mathrm{BCl}-2$ expression and Rho A prenylation. Atherosclerosis. 2002;161(1):17-26. https://doi.org/10.1016/S0021-9150(01 )00613-X.

39. Chapman-Shimshoni D, Yuklea M, Radnay J, Shapiro H, Lishner M. Simvastatin induces apoptosis of B-CLL cells by activation of mitochondrial caspase 9. Exp Hematol. 2003;31(9):779-83. https://doi.org/10.1016/S0301-4 72X(03)00192-9.

40. Wong WWL, Dimitroulakos J, Minden MD, Penn LZ. HMG-CoA reductase inhibitors and the malignant cell: the statin family of drugs as triggers of tumor-specific apoptosis. Leukemia. 2002;16(4):508-19. https://doi.org/10.1 038/sj.leu.2402476.

41. Knapp AC, Huang J, Starling G, Kiener PA. Inhibitors of HMG-CoA reductase sensitize human smooth muscle cells to Fas-ligand and cytokine-induced cell death. Atherosclerosis. 2000;152(1):217-27. https://doi.org/10.1016/ S0021-9150(99)00462-1.

42. Baima B, Sticherling M. Apoptosis in different cutaneous manifestations of lupus erythematosus. Br J Dermatol. 2001;144(5):958-66. https://doi.org/10.1 046/j.1365-2133.2001.04182.x

43. Rovere P, Sabbadini MG, Fazzini F, Bondanza A, Zimmermann VS, Rugarli C, et al. Remnants of suicidal cells fostering systemic autoaggression: apoptosis in the origin and maintenance of autoimmunity. Arthritis \& Rheumatism. 2000;43(8):1663-72. https://doi.org/10.1002/1529-0131(200008)43:8<1663::A ID-ANR1>3.0.CO;2-1.

44. Van Halm V, Nielen M, Nurmohamed M, Van Schaardenburg D, Reesink $H$, Voskuyl A, et al. Lipids and inflammation: serial measurements of the lipid profile of blood donors who later developed rheumatoid arthritis. Ann Rheum Dis. 2007;66(2):184-8. https://doi.org/10.1136/ard.2006.051672.

45. Alipour A, van Oostrom AJ, Izraeljan A, Verseyden C, Collins JM, Frayn KN, et al. Leukocyte activation by triglyceride-rich lipoproteins. Arterioscler Thromb Vasc Biol. 2008;28(4):792-7. https://doi.org/10.1161/ATVBAHA.107.1 59749.

46. Van Oostrom A, Rabelink T, Verseyden C, Sijmonsma T, Plokker H, De Jaegere PT, et al. Activation of leukocytes by postprandial lipemia in healthy volunteers. Atherosclerosis. 2004;177(1):175-82. https://doi.org/10.1016/j.a therosclerosis.2004.07.004.

47. Meijssen S, Van Dijk H, Verseyden C, Erkelens D, Cabezas MC. Delayed and exaggerated postprandial complement component 3 response in familial combined hyperlipidemia. Arterioscler Thromb Vasc Biol. 2002;22(5):811-6. https://doi.org/10.1161/01.ATV.0000014079.98335.72.

48. Chan KW, Felson DT, Yood RA, Walker AM. The lag time between onset of symptoms and diagnosis of rheumatoid arthritis. Arthritis Rheum. 1994;37(6): 814-20. https://doi.org/10.1002/art.1780370606.

49. Sathasivam S, Lecky B. Statin induced myopathy. Bmj. 2008;337(nov06 3): a2286. https://doi.org/10.1136/bmj.a2286.

50. Symmons DP, Bankhead CR, Harrison BJ, Brennan P, Barrett EM, Scott DG, et al. Blood transfusion, smoking, and obesity as risk factors for the development of rheumatoid arthritis: results from a primary care-based incident case-control study in Norfolk, England. Arthritis Rheum. 1997;40(11): 1955-61. https://doi.org/10.1002/art.1780401106.

51. Di Giuseppe D, Bottai M, Askling J, Wolk A. Physical activity and risk of rheumatoid arthritis in women: a population-based prospective study. Arthritis Res Ther. 2015;17(1):1-7.

\section{Publisher's Note}

Springer Nature remains neutral with regard to jurisdictional claims in published maps and institutional affiliations.

Ready to submit your research? Choose BMC and benefit from:

- fast, convenient online submission

- thorough peer review by experienced researchers in your field

- rapid publication on acceptance

- support for research data, including large and complex data types

- gold Open Access which fosters wider collaboration and increased citations

- maximum visibility for your research: over $100 \mathrm{M}$ website views per year

At BMC, research is always in progress.

Learn more biomedcentral.com/submissions 